\title{
The Application of LENR to Synergistic Mission Capabilities
}

\author{
Douglas P. Wells* \\ NASA Langley Research Center, Hampton, VA 23602 \\ Dimitri N. Mavris ${ }^{\dagger}$ \\ Georgia Institute of Technology, Atlanta, Georgia 30332-0150
}

\begin{abstract}
This paper presents an overview of several missions that exploit the capabilities of a Low Energy Nuclear Reaction (LENR) aircraft propulsion system. LENR is a form of nuclear energy and potentially has over 4,000 times the energy density of chemical energy sources. It does not have any harmful emissions or radiation which makes it extremely appealing. The global reliance on crude oil for aircraft energy creates the opportunity for a revolutionary change with LENR. LENR will impact aircraft performance capabilities, military capabilities, the environment, the economy, and society. Although there is a lot of interest in LENR, there is no proven theory that explains it. Some of the technical challenges are thermal runaway and start-up time. This paper does not explore the feasibility of LENR and assumes that a system is available. A non-dimensional aircraft mass (NAM) ratio diagram is used to explore the aircraft system design space. The NAM ratio diagram shows that LENR can enable long range and high speed missions. The design space exploration led to the conclusion that LENR aircraft would be well suited for high altitude long endurance (HALE) missions, including communications relay and scientific missions for hurricane tracking and other weather phenomena, military intelligence, surveillance, and reconnaissance (ISR) and airspace denial missions, supersonic passenger transport aircraft, and international cargo transport. This paper describes six of those missions.
\end{abstract}

\section{Nomenclature}

$\begin{array}{ll}\text { AISI } & =\text { American Iron and Steel Institute } \\ \mathrm{Btu} & =\text { British thermal unit } \\ \mathrm{H}_{2} & =\text { hydrogen } \\ \mathrm{HALE} & =\text { high altitude long endurance } \\ \mathrm{ISR} & =\text { intelligence, surveillance, and reconnaissance } \\ \mathrm{Ku} & =\text { k-under } \\ \mathrm{LENR} & =\text { low energy nuclear reaction } \\ \mathrm{LNG} & =\text { liquid natural gas } \\ N A S A & =\text { National Aeronautics and Space Administration } \\ N A M & =\text { non-dimensional aircraft mass } \\ N O x & =\text { nitrogen oxides } \\ \mathrm{Pb} & =\text { lead } \\ U . S . & =\text { the United States of America } \\ U A S & =\text { unmanned aircraft systems } \\ U H F & =\text { ultra high frequency } \\ W h & =\text { watt-hour } \\ \mathrm{Zn} & =\text { zinc }\end{array}$

\footnotetext{
* Aerospace Engineer, Aeronautics Systems Analysis Branch, Mail Stop 442, AIAA Member.

$\uparrow$ Boeing Professor of Advanced Aerospace Systems Analysis and Director of Aerospace Systems Design Laboratory, Daniel Guggenheim School of Aerospace Engineering. Associate Fellow AIAA.
} 


\section{Introduction}

$\mathrm{W}$ HEN will the next revolutionary change occur in aviation? For decades, aircraft have made incremental changes and look virtually identical to the aircraft that were designed 40 to 50 years ago. Aeronautics research has focused on gaining every fraction of a percent of efficiency toward performance improvement. Most of these incremental improvements have come from increased understanding and exploitation of the underlying physics of the various disciplines or by advances in new technologies. The continuous trend towards rising fuel prices, along with the increased demand for energy resources has compounded this problem and if unaltered it could potentially lead to mandatory stringency regulations, which in turn could limit transportation growth. In addition, aircraft manufacturers are also attempting to reduce noise and hazardous emissions to meet environmental regulations that are also progressively getting more stringent.

All these conflicting demands create major challenges for the design of future aircraft. New energy sources have the potential to solve these challenges. One technology that has the potential to address this is referred to as Low Energy Nuclear Reactions (LENR). LENR is a form of nuclear energy that potentially has over 4,000 times the density of chemical energy with zero greenhouse gas or hydrocarbon emissions. ${ }^{1}$ This paper presents the motivation for looking at LENR as a viable concept for use in aircraft propulsion systems which will enable new and enhanced mission capabilities.

LENR was first introduced as cold fusion. By initially describing it as cold fusion the intention was to distinguish it from mainstream fusion approaches which relied on extremely high temperatures to initiate nuclear reactions. For example, the fusion bomb requires an initial fission bomb to generate the high temperatures that enable the fusion reaction. ${ }^{2}$ In contrast, LENR requires relatively low temperatures or energy stimulus to initiate reactions. Since its introduction, many have debated LENR's existence, and the underlying theory behind it. To date, there is no generally accepted underlying theory describing the LENR reaction; however, recent tests have shown promising results. ${ }^{3}$ LENR is controversial because it is difficult to consistently reproduce the experimental results. Furthermore, debate continues on the credibility of the positive results and the fact that the experimental reactors could be pre-loaded with energy. For the purpose of this research, it is assumed that the claims made about LENR are valid and that a working system exists. The objective of this research is to identify and define aircraft missions that either exploit the unique capabilities of LENR or are enabled by a LENR propulsion system. Furthermore, LENR benefits are contrasted side by side with other alternative sources of energy to highlight its potential benefit. More specifically, a high-level analysis was performed to explore the design space of a LENR aircraft, under different potential scenarios of a long endurance mission.

\section{Low Energy Nuclear Reaction}

Low Energy Nuclear Reactions (LENR) is a type of nuclear energy based on the weak force. It theoretically has up to eight million times the energy density of chemical sources. Table 1 shows the theoretical maximum energy density for LENR, fusion, and fission. LENR has similar characteristics to fission and fusion, but there is no harmful radiation or hazardous waste. Detection of neutron or gamma radiation from experimental reactors is rare. Little if any shielding is expected for radiation protection. LENR's history can

Table 1. Nuclear energy comparison ${ }^{1}$

\begin{tabular}{|l|l|l|l|}
\hline & LENR & Fusion & Fission \\
\hline $\begin{array}{l}\text { Theoretical } \\
\text { Max Energy } \\
\text { Density }\end{array}$ & $\begin{array}{l}8,000,000 \\
\text { times } \\
\text { chemical }\end{array}$ & $\begin{array}{l}7,300,000 \\
\text { times } \\
\text { chemical }\end{array}$ & $\begin{array}{l}1,900,000 \\
\text { times } \\
\text { chemical }\end{array}$ \\
\hline $\begin{array}{l}\text { Fundamental } \\
\text { Force }\end{array}$ & Weak & Strong & Strong \\
\hline
\end{tabular}
aimed at refining the theory and on creating a working reactor. A promising theory was reported in 2006, known as the Widom-Larsen Theory. ${ }^{5}$ It is based on the standard model and uses conventional physics. LENR is scalable, portable and has the potential to replace all fossil fuel usage. ${ }^{1}$ A recent report that was released in May 2013 shows the results of two LENR reactor tests performed in December 2012 and March 2013. ${ }^{3}$ The reactors were cylindrical in shape and measured about $33 \mathrm{~cm}$ long and $9 \mathrm{~cm}$ in diameter. The inner cylinder was made of American Iron and Steel Institute (AISI) 310 steel, an outer shell of silicon nitride ceramic, and two end caps of AISI 316 steel. The reaction materials consist of hydrogen loaded nickel powder. Table 2 shows the results of the two reactor tests. 


\section{Motivation}

Among the biggest motivators for LENR is the current need to generate viable and clean energy to meet ever-increasing energy demands. To illustrate this point, figure 1 shows the total crude oil production and consumption in the United States from the year 1980 and projected out to $2040 .{ }^{6}$ Two major conclusions that can be taken from this figure are that (1) the U.S. crude oil consumption is expected to increase out to 2040, and (2) production is not expected to meet the demand. Figure 2 shows the U.S. Energy Information Agency crude oil prices from the year 1980 and projected out to $2040 .{ }^{6}$ One conclusion that can be made from this figure in the reference case, is that prices are expected to increase out to the year 2040. The two figures together show that crude oil will be an expensive source of energy that will be in high demand.

LENR methods have the potential to change the cost of energy in the future, which would be a revolutionary change. It is a fundamentally different type of energy compared to current resources, which could potentially introduce a higher payoff. This new source of energy is incentivizing a reevaluation of missions and architectures, much as changes were required on airframes utilizing gas turbine engines. The early gas turbine powered aircraft (or jets) looked like the previous piston-engine aircraft, but carried jet engines and performed the same types of missions with marginal performance improvement. Once research and testing provided more powerful jet engines that were better integrated with their airframes, higher operating altitudes and speeds became practical. The same

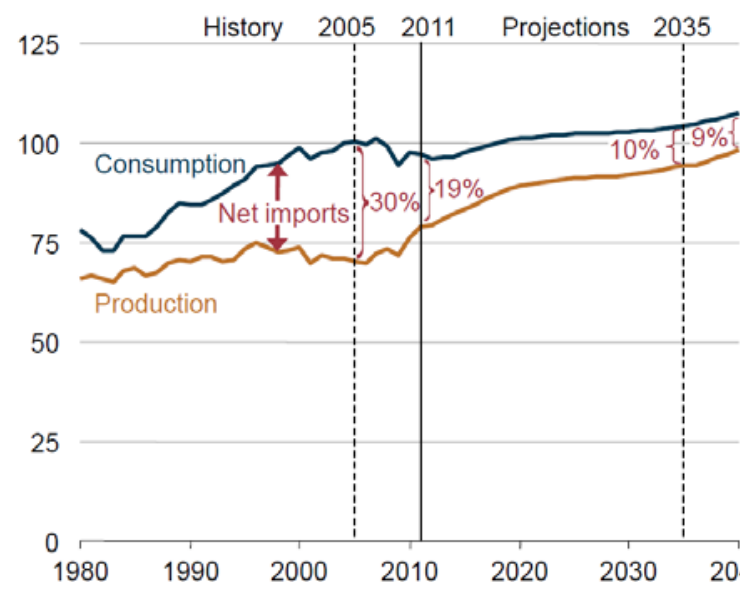

Figure 2. Total U.S. energy production and consumption, 1980-2040 (quadrillion Btu) ${ }^{6}$

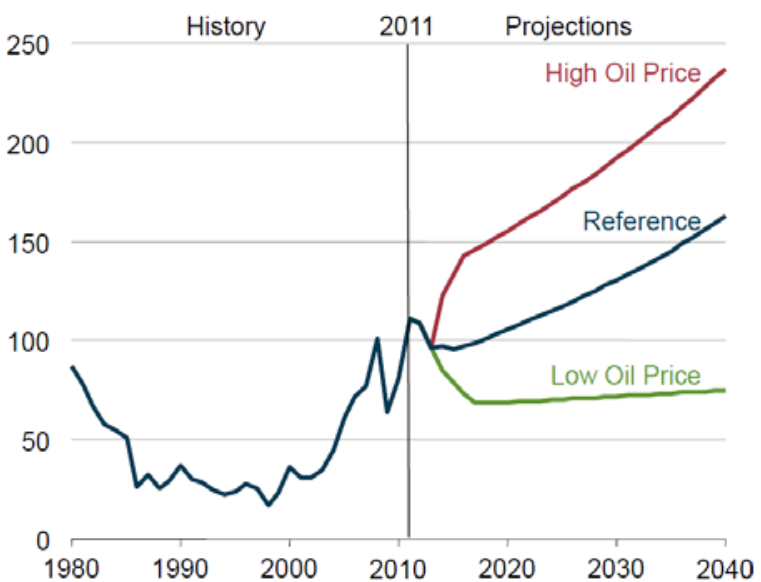

Figure 1. Average annual Brent spot crude oil prices in three cases, 1980-2040 (2011 USD per barrel) ${ }^{6}$

scenario should be true for LENR powered aircraft. LENR is a revolutionary technology whose potential cannot be achieved through evolutionary integration onto existing airframes. It should be very advantageous to design the rest of the aircraft around the LENR technology that has such radically different characteristics.

\section{A. Impact}

The aircraft performance characteristics are anticipated to be different due to LENR. Aircraft would be capable of practically unlimited range and endurance. This capability would affect how aircraft are designed. Range and endurance may no longer actively constrain the design space. LENR reactors operate on small amounts of fuel for weeks or months at a time, which will lead to virtually negligible fuel fractions and constant weight missions. LENR would also impact mission capabilities, as it would also enable missions like communications relay, hurricane tracking, and polar ice observation to be performed practically.

LENR would have a large impact on military applications. The U.S. military is currently experiencing increased expenditures on fuel, ${ }^{7}$ which can be eliminated with LENR. Energy independence would be a strong possibility for the future, and the military forces would be able to invest energy related savings in developing new capabilities (e.g. such as ultra-long endurance missions) and acquiring assets. 
There are several environmental impacts due to the use of LENR. LENR does not burn fossil fuels, thus reducing emissions of all kinds. An LENR reactor can operate on amounts of reactants that are on the order of grams for multiple months to years, if compared to a gas turbine engine that requires thousands of pounds of fuel to operate for several hours. The importance of decreasing emissions and fuel consumption is evident by NASA's technology goals for future subsonic vehicles of reducing fuel consumption, emissions, and noise levels. ${ }^{8}$ LENR directly addresses two of these goals and could use additional energy from the system to actively reduce aircraft noise or carry additional noise reduction technologies.

\section{B. Challenges}

LENR faces some common and some unique challenges as the technology is applied to aircraft. As of now, none of the proposed theories have been generally accepted. A valid LENR theory would be especially useful to understand the characteristics of the process. So far, only experimental reactors have been built to date. Most experimental systems are very different from production systems in terms of reliability and safety. Manufacturers of LENR reactors will need to address any concerns that arise as the reactors progress toward commercialization. Another challenge LENR must overcome is the problem of thermal runaway, which occurs when the reactor temperature reaches some critical point at which thermal stability diverges. Thermal runaway results in melting of the reactor materials. There will most likely be other safety concerns related to the high energy density of LENR reactors. Storing high amounts of energy is always potentially dangerous. Public acceptance will be another challenge, as the public needs to feel comfortable with the LENR process and safety measures that address technical operation. The word "nuclear" in the name "LENR" may intimidate potential customers and manufacturers might consider a different name for marketing purposes.

LENR is not a mature technology ready to be integrated into an aircraft today. ${ }^{9}$ There are no heat engines or control systems ready to integrate with a LENR reactor. Research is needed to determine the best way to use the heat generated from the reactor and convert it to mechanical energy for use as a propulsion system. The control system will be critical because of the thermal runaway problem. The system must be carefully designed to avoid the critical temperature point. Some missions may require quick turn-around times for the aircraft and the LENR start-up time may become a problem. Another challenge is aircraft noise. LENR does not directly address the aircraft noise. However, there may be excess energy available to power or carry noise reduction technologies.

\section{Aircraft Energy Sources}

Boeing, under contract with NASA, has researched several alternative energy sources for use in future passenger transport aircraft to reach the NASA environmental goals. ${ }^{9}$ Some of the alternative energy sources (e.g. hydrogen), have a long history of research in aeronautics. ${ }^{10-12}$ The same NASA report examined liquid natural gas and conventional fuel / hybrid electric sources. LENR was identified as a high pay-off source of energy in the report. To avoid repeating research, a brief description of the energy sources that were considered for future aircraft in the NASA report are presented below. ${ }^{9}$

\section{A. Conventional Fuel}

Aircraft have traditionally been powered by conventional fuels which are refined from petroleum, while jet fuel is the industry standard for commercial operations. Jet fuel is a very good source of energy and this is why it has been used widely and for a long period of time. It has high energy density and the high specific energy of 12,000 $\mathrm{Wh} / \mathrm{kg}$ over a wide range of common operational temperatures and pressures. ${ }^{13}$ Even so, NASA and others are pursuing ways to reduce the amount of jet fuel required for aircraft missions because of cost and emissions.

\section{B. Electric}

Electric energy is rapidly increasing in popularity as a result of increased research directed at its increased utilization on board aircraft. A simple electric power system consists of batteries or solar cells and an electric motor. The batteries store chemical energy and convert it to electrical energy, while motors convert electrical energy into mechanical energy. There are only a few aircraft currently using electricity for propulsion. Figure 3 shows the energy of several types of batteries including lithium-ion and zinc-air. Depending on the electricity source, there may be no emissions from the propulsion system. 


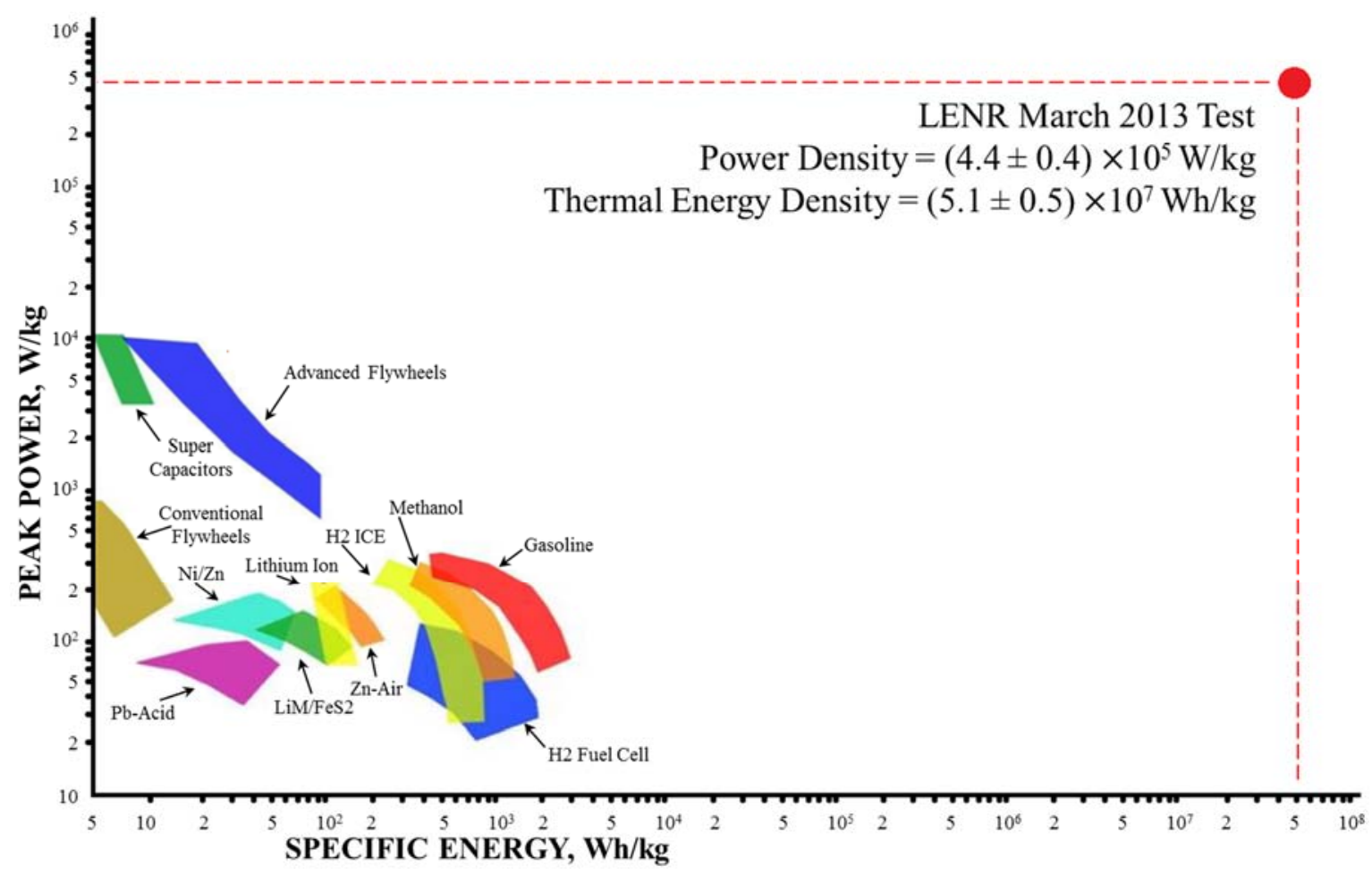

Figure 3. Ragone plot of various energy sources ${ }^{3}$

\section{Conventional Fuel / Hybrid Electric}

The conventional fuel / hybrid electric energy is a combination of the previous two sources and can range widely in proportion. Hybrid systems are of interest because significant benefits from both sources can be leveraged. However, both sources have environmental impacts (e.g. emissions) that still apply.

\section{Hydrogen and Liquid Natural Gas}

Hydrogen and liquid natural gas (LNG) have been considered for several decades as options for aircraft propulsion. Lockheed studied the CL-400 Suntan in the 1950s, which used a hydrogen fueled propulsion system. ${ }^{12}$ A hydrogen or LNG system would consist of storage tanks, feed and distribution systems, and an interface for the fuel. ${ }^{9}$ LNG and hydrogen have higher specific energy than jet fuel: $13,889 \mathrm{Wh} / \mathrm{kg}$ and $33,333 \mathrm{Wh} / \mathrm{kg}$ respectively. ${ }^{13}$ This type of propulsion system would still require combustion and thus will also have fuel consumption and emissions.

\section{E. Fuel Cell}

Fuel cells convert fuel directly into electricity through chemical reactions. A fuel cell propulsion system could support a hybrid system or power an electric motor. Figure 3 also shows the energy for a hydrogen $\left(\mathrm{H}_{2}\right)$ fuel cell. A fuel cell propulsion system powers an electric motor producing emissions and consuming fuel; however, in a hydrogen fuel cell, water is the byproduct and may have no impact on the environment.

\section{F. LENR}

Low Energy Nuclear Reactions is a source of thermal energy. It is an immature technology that requires further research to determine the best propulsion system integration on a vehicle platform. LENR has the highest specific energy of the alternative energy sources mentioned at about $51,000,000 \mathrm{Wh} / \mathrm{kg} .{ }^{3}$ This is a conservative estimate from the recent LENR reactor test that was conducted in March 2013. The Ragone plot in Fig. 3 shows that LENR has huge potential as an energy source. An LENR powered system would consume a very small amount of fuel because it requires a small reaction mass. No chemicals are added to the air during operation so no chemical emissions exist. Noise emissions will still be a concern because the thermal energy still has to be converted into thrust; however, the abundant energy available could be used to power noise reduction technologies. The small 
reaction mass enables an aircraft to fly constant-weight missions combined with no harmful emissions and an extremely high energy density make LENR attractive for aircraft propulsion systems.

\section{LENR System Design Space Exploration}

A design space exploration helped to identify the characteristics of using LENR for a propulsion system in aircraft. Dr. Taewoo Nam's Ph.D. thesis presented a visual design space called the Non-dimensional Aircraft Mass (NAM) ratio diagram. ${ }^{14}$ It is constructed in a way to help a designer choose the most suitable propulsion system for a given mission. For this initial exploration, it was used to compare a LENR system to currently available systems that perform High Altitude Long Endurance (HALE) or similar missions. Figure 4 shows a notional NAM ratio diagram. The NAM ratio diagram is composed of four quadrants: power that describes aerodynamics and propulsion system weight, mass that describes advanced materials and integration, energy that describes aerodynamics and energy efficiency, and mission that describes vehicle performance. The power space maps the cruise velocity to the propulsion system weight fraction. The mass space maps the propulsion system weight fraction to the energy weight fraction. The energy space maps the energy weight fraction to the mission range. Finally, the mission space maps the mission range to the cruise velocity.

Figure 5 shows the procedure to plot an aircraft on a notional NAM ratio diagram. First, a design cruise velocity was selected. Next, the propulsion

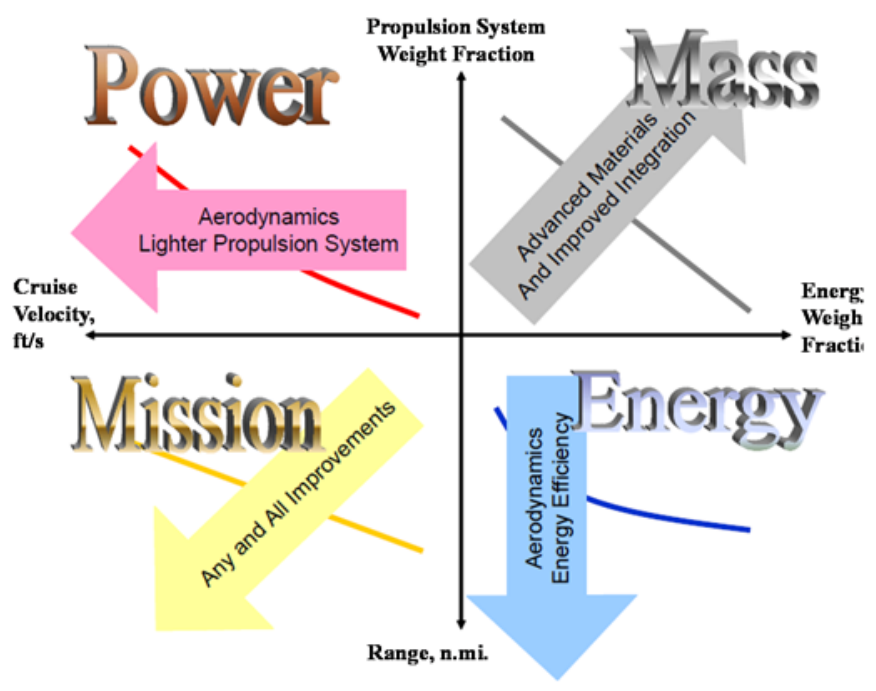

Figure 4. Notional NAM ratio diagram ${ }^{14}$ system weight fraction was calculated using Eq. (1),

$$
\frac{W_{P S}}{W_{T O}}=\frac{\beta V}{\alpha v_{P S} L / D}
$$

where: $\frac{W_{P S}}{W_{T O}}$ is the propulsion system weight fraction, $\beta$ is the aircraft weight fraction, $V$ is the cruise velocity, $\alpha$ is the thrust lapse, $v_{P S}$ is the propulsion system specific power, and $L / D$ is the cruise lift-to-drag ratio. This step mapped the cruise velocity to the propulsion system weight fraction to plot in the power space. The most efficient aircraft have a higher specific power propulsion system and thus a lower propulsion system weight fraction. The next step was to calculate the total energy weight fraction using Eq. (2),

$$
\frac{W_{T E}}{W_{T O}}=\frac{1-\frac{W_{E}}{W_{T O}}-\frac{W_{P L}}{W_{T O}}-\left(1+e_{P S}\right) \frac{W_{P S}}{W_{T O}}}{\left(1-e_{T E}\right)}
$$

where: $\frac{W_{T E}}{W_{T O}}$ is the total energy weight fraction, $\frac{W_{E}}{W_{T O}}$ is the aircraft empty weight fraction, $\frac{W_{P L}}{W_{T O}}$ is the aircraft payload weight fraction, $e_{P S}$ represents the impact on the empty weight from integrating an unconventional propulsion system, and $e_{T E}$ represents the impact on the empty weight from integrating total energy source. The total energy variables included both consumable and non-consumable energy sources. This step mapped the propulsion system weight fraction to the energy weight fraction to plot in the mass space. The aircraft with the lightest weight materials is the most efficient in the mass space. Lightweight materials lower the aircraft empty weight fraction and propulsion system weight fraction, while increasing the available weight for fuel. The next step was to calculate the range using Eq. (3),

$$
R=v_{N E} \Pi_{\mathrm{\eta}} \frac{L}{D} \frac{W_{N E}}{W_{T O}}
$$


where: $R$ is the mission range capability, $\Pi_{\mathrm{y}}$ is the Propulsion system efficiency, and $\frac{W_{N E}}{W_{T O}}$ is the non-consumable energy source weight fraction. This step mapped the energy weight fraction to the mission range to plot in the energy space. The most energy efficient aircraft have a higher efficiency and specific power propulsion system and thus a longer range. The last step was to map the range and velocity to the mission space. The best aircraft for the given mission will have a higher cruise velocity and cruise range capability. This quadrant gives the mission design space capabilities for a given aircraft.

Figure 6 shows the results of the design space exploration exercise. The results are presented as a NAM ratio diagram that plots eleven existing aircraft that were designed for high altitude and/or long endurance missions, twelve HALE aircraft that were designed for a NASA study, and two sets of LENR powered HALE aircraft. Aircraft included in this data set are the AeroVironment/NASA Helios, Aurora

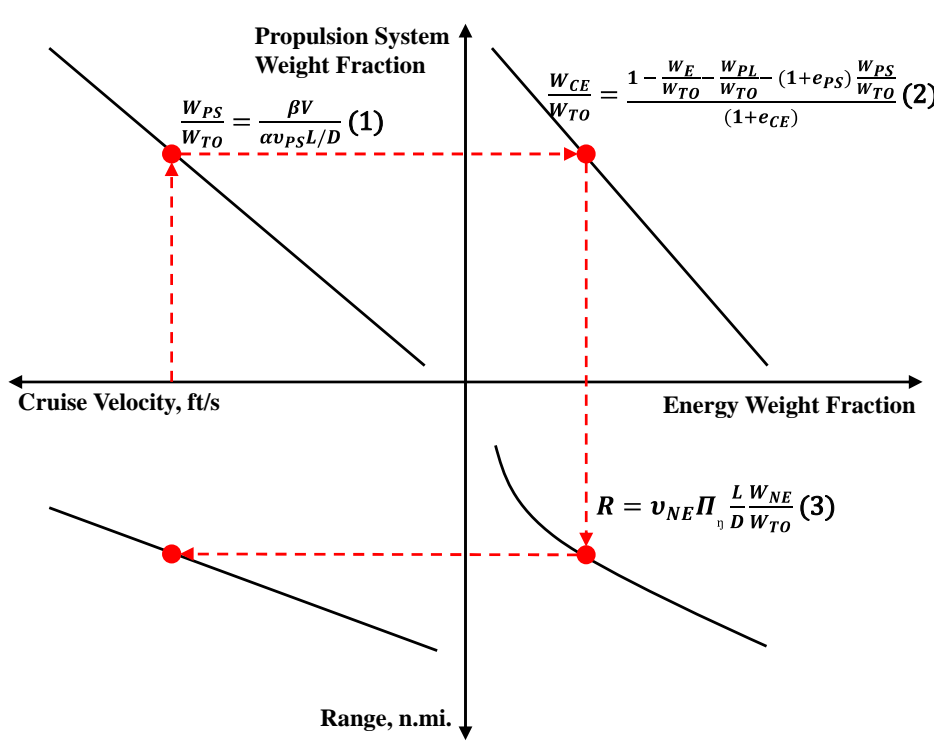

Figure 5. NAM ratio diagram plotting process ${ }^{14}$

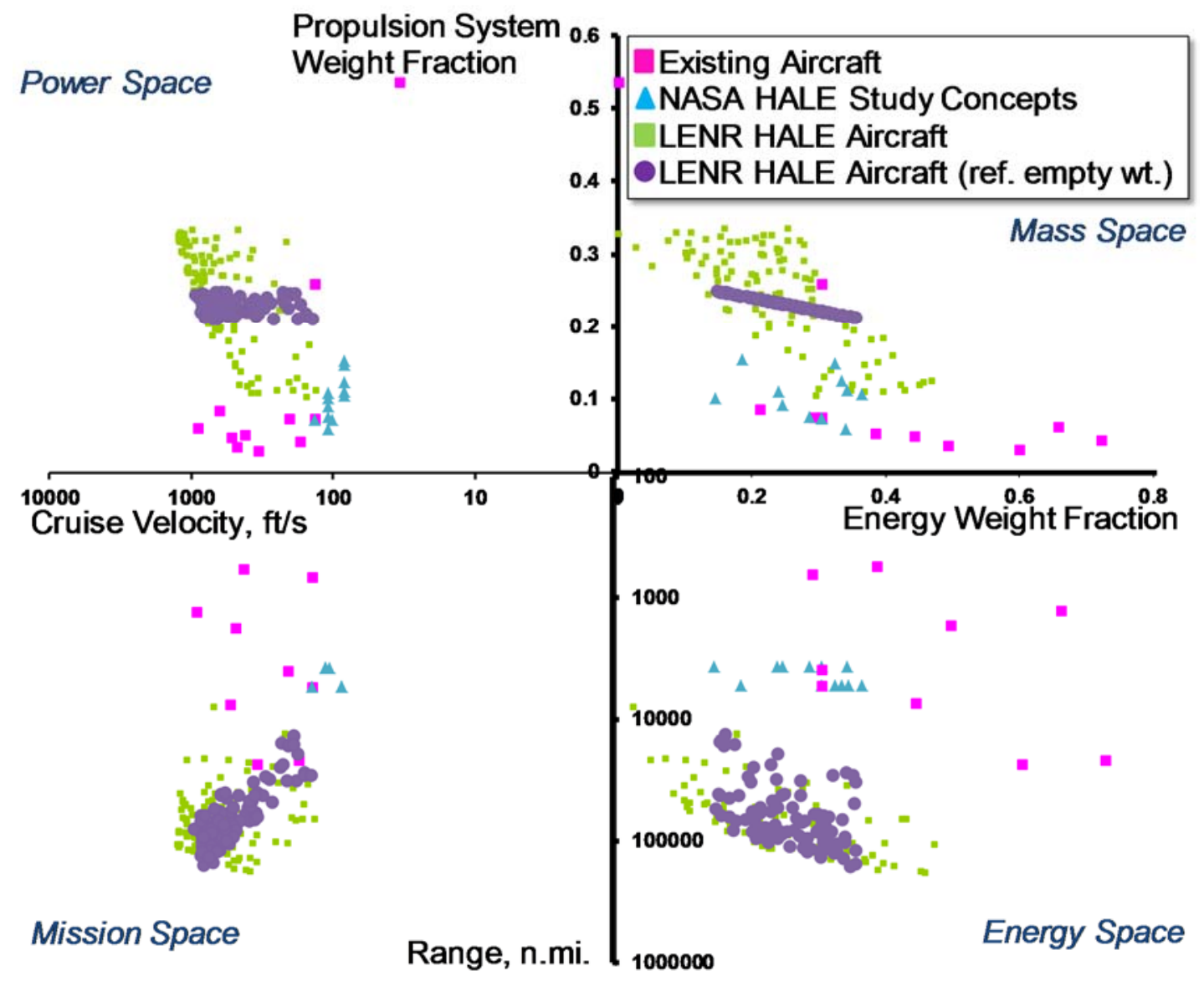

Figure 6. NAM ratio diagram of existing high altitude and long endurance vehicles, solar regenerative aircraft from a NASA studv, and notional LENR powered aircraft 
Flight Sciences Orion, Boeing Condor, Phantom Eye, and Phantom Ray, General Atomics Predator, L-3 Communications Mobius, Lockheed-Martin Dark Star, Northrop Grumman Global Hawk, Rutan Voyager, and Scaled Composites Proteus. The NASA HALE study aircraft included the solar regenerative conceptual designs from [15]. The configurations from the NASA study include flying wings, a truss-braced flying wing, a joined wing, and a multi-surface flying wing. The LENR HALE aircraft were based on the empty and propulsion system weight fractions from the NASA HALE study aircraft and the LENR power and energy densities in [3]. The LENR HALE aircraft (reference empty weight) data set were similar to the first LENR data set, but the empty weight fractions were based on the NASA HALE study aircraft and the equations were used to solve for the cruise velocity.

The assumptions that were used in the NAM ratio diagram equations were including stationary atmosphere with no wind and steady level flight, which implied that thrust equaled drag and lift equaled weight. The LENR HALE aircraft data set had additional assumptions of constant weight throughout the mission, cruise lift to drag ratio between 5 and 30, propulsion system efficiency between 0.2 and 0.25 , cruise velocity between 100 and 1960 feet per second, and a thrust lapse rate of 0.21 . The LENR HALE aircraft with the referenced empty weight data set had the same cruise lift to drag ratio, propulsion system efficiency, and thrust lapse rate assumptions. However, the empty weight fraction was between 0.7 and 0.8 , which was based on the solar regenerative aircraft from the NASA HALE study. A range of values was used for the LENR aircraft to explore a range of aircraft designs at a conceptual level.

A turbofan engine architecture was assumed for the LENR aircraft propulsion systems based on a LockheedGeorgia report from 1977. The report showed open and closed Brayton and Rankine cycle turbofan engine architectures for a nuclear energy source. ${ }^{16}$ Figure 7 shows the open Brayton cycle nuclear propulsion system schematic from the Lockheed-Georgia report. This propulsion architecture was assumed because there is a large amount of research and experimental data available. The combustor section of a turbofan engine was replaced with nuclear thermal energy using heat exchangers. The particular architecture in Fig. 7 had a dual mode capability and also used a chemical fueled combustor. The engine design characteristics are shown in Table 3 . The engine was designed for a $0.75 \mathrm{Mach}, 31,000 \mathrm{ft}$. altitude cruise. The aircraft had four engines, over 1.5 million pound ramp weight, and virtually unlimited range. ${ }^{16} \mathrm{~A}$ similar architecture was assumed for the LENR aircraft. A LENR reactor replaced

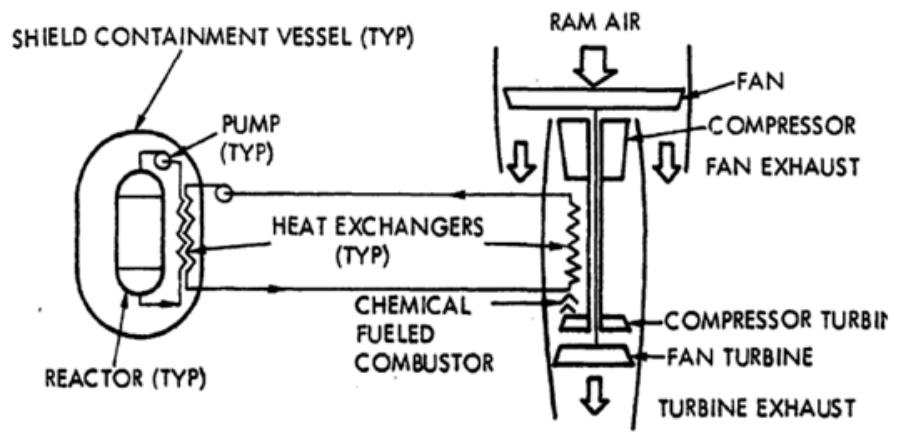

Figure 7. Open Brayton Cycle nuclear aircraft propulsion system schematic from 1977 Lockheed-Georgia report ${ }^{16}$

Table 3. Design characteristics of the LockheedGeorgia baseline nuclear engine ${ }^{16}$

\begin{tabular}{|l|l|}
\hline Rated Thrust (lb) & 84,800 \\
\hline Fan Pressure Ratio & 1.3 \\
\hline Overall Pressure Ratio & 12 \\
\hline $\begin{array}{l}\text { Turbine Inlet Temperature, } \\
\text { Cruise (deg. F) }\end{array}$ & 1,600 \\
\hline Core Lifetime (h) & 10,000 \\
\hline Fuel (lb) & 2,200 \\
\hline Coolant & Lithium \\
\hline
\end{tabular}
combustor was included. The propulsion system architecture should be the focus of future research. Nuclear aircraft engine studies from the past are a good start, but there may be better options with current technology and the emergence of electric prowered aircraft.

The NAM ratio diagram proved to be an effective tool for the design space exploration. The power space in Fig. 6 showed a general trend that the LENR HALE aircraft propulsion system weight fraction increases with cruise velocity. The general trend led to an intuitive conclusion that a larger propulsion system can increase cruise velocity. However, that data set contained a limited number of points and does have some outliers. The LENR HALE aircraft (Ref. empty weight) data set did not show the same trend and indicated that the propulsion system weight fraction was independent of the cruise velocity. This data set plots aircraft architectures with similar geometry and weight parameters, which explains why the data points are so close together. The mass space showed that LENR aircraft are able to simultaneously achieve improved propulsion system weight fractions and energy weight fractions. The energy space showed the LENR aircraft are capable of extreme range with low energy weight fractions. This capability is a result of the high energy density of the LENR technology. The mission space shows that LENR powered aircraft are capable of high cruise velocity and long range. The LENR HALE aircraft (ref. empty weight) data set in Fig. 6 shows that cruise velocity and range have an increasing linear relationship. The narrow range of empty weight inputs for this data set kept the 
data points close in the mission space and made the cruise velocity and range a direct function of the lift-to-drag ratio. Three conclusions were drawn from the design space exploration: (1) LENR powered aircraft enable extremely long range missions, (2) the high power density can be used to obtain high cruise velocity, and (3) LENR decouple the propulsion system size from the power capability. The abundant energy from an LENR reactor can be applied to the traditional aircraft design constraints like range/endurance and speed.

\section{Mission Descriptions}

The objective of this research was to identify missions that exploit the unique capabilities of a LENR propulsion system or are enabled by LENR. Some of these missions include HALE, high speed, and heavy long range. The HALE missions will most likely be unmanned because of the long endurance, limit of human pilot/operator demonstrated in the around the world flights. Communications relay, hurricane tracking, border patrol, port surveillance, disaster relief support, animal tracking, and high altitude atmospheric research are examples of civilian HALE missions. Military missions include intelligence, surveillance, and reconnaissance (ISR), persistent surveillance, and airspace denial. Several of these missions have been studied in other papers and reports. Brief descriptions are presented for the reader's convenience.

\section{A. Communications Mission}

The communications relay mission requires a vehicle to carry a payload that will relay communications. This has civilian and military applications. "HALE UAV platforms have the potential to serve as effective, low cost communications relay systems due to their long endurance, large ground footprint (compared to cell phone towers), flexibility, and relatively low acquisition and operating costs (compared to satellites)". ${ }^{15}$ A communications relay mission is well defined in [15]

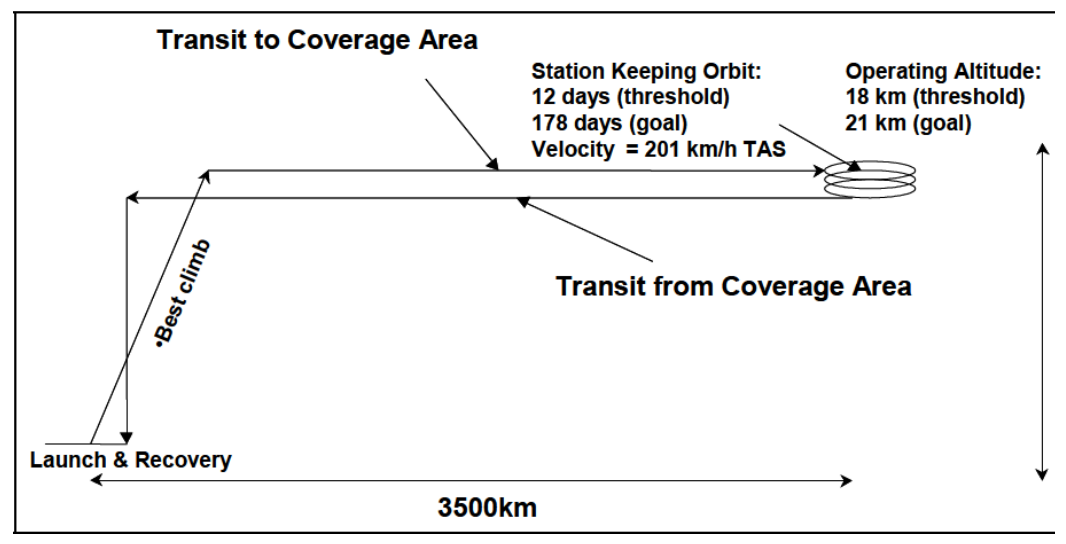

Figure 8. Communications relay mission profile ${ }^{15}$

and briefly repeated in this subsection. Figure 8 shows the communications relay mission profile. The vehicle has a requirement to stay on station $99.9 \%$ of the time which means it must be within a position cylinder with a $4,000 \mathrm{~m}$ radius and 3,000 $\mathrm{m}$ height at the operating altitude. The payload requirements are $200 \mathrm{~kg}, 0.1 \mathrm{~m}^{3}$ of volume, and 1.5 $\mathrm{kW}$ of power.

\section{B. Hurricane Tracking Mission}

The hurricane tracking mission requires a vehicle to intercept and then escort a hurricane and perform maneuvers to drop expendable payload. A hurricane tracking mission is also well defined in [15] and will be briefly repeated in this subsection. Figure 9 shows the hurricane tracking mission profile. The vehicle is required to escort or fly with the hurricane for at least 14 days. The payload for this mission consists of radar and sensors. The payload requirements are $500 \mathrm{~kg}, 3$ $\mathrm{m}^{3}$ of volume, and $2.5 \mathrm{~kW}$ of power.

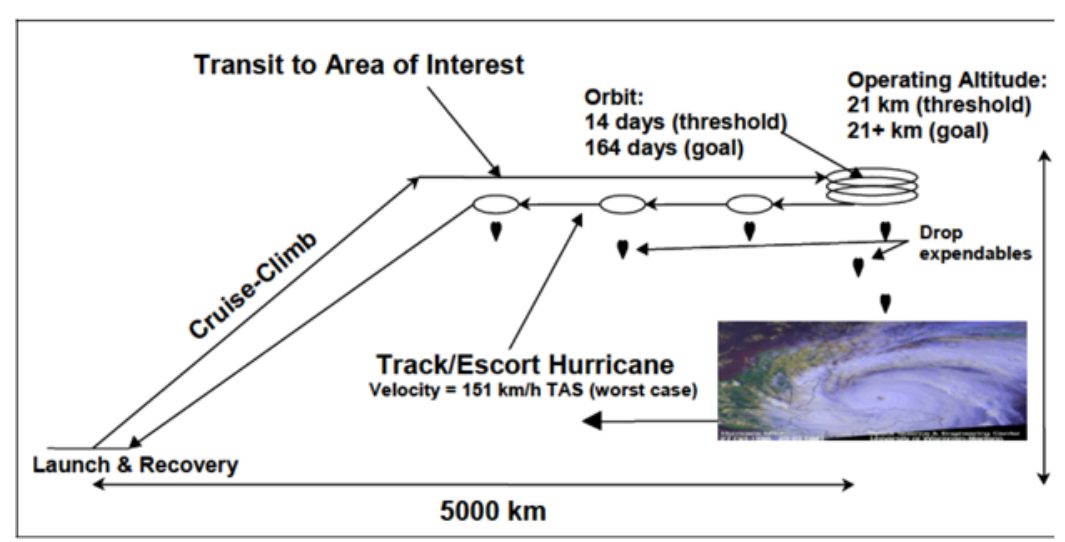

Figure 9. Hurricane tracking mission profile ${ }^{15}$

This mission also required expendable sensors and/or unmanned aerial vehicles. The expendable payload requirements are $850 \mathrm{~kg}$ and $11 \mathrm{~m}^{3}$ of volume. 


\section{Intelligence, Surveillance, and Reconnaissance (ISR)}

The ISR mission supports an important military capability. Some ISR systems collect basic information to support various analytical products and others acquire data for specific weapon systems. Northrop Grumman's RQ-4 Global Hawk unmanned aircraft system (UAS) is one example of an aircraft that currently supports this capability. LENR's long range and endurance capabilities will allow it to replace some satellite capabilities as well. Global Hawk is capable of surveying large areas with pinpoint accuracy which can give the military decision-makers the crucial information they need on enemy location and resources in real-time. Global Hawk's capabilities are shown in Table 4. It carries electro-optical, infrared, and synthetic aperture radar sensors, $\mathrm{Ku}$ band satellite communications data link, common line of sight data link, UHF satellite communication/line of sight, Inmarsat satellite communication, air traffic control voice, and secure voice communications. ${ }^{17}$

\section{Airspace Denial Mission}

The United States Air Force submitted a proposal in 1959 for a nuclear powered patrol aircraft. The proposed vehicle was called continuously airborne missile-launcher and low-level (CAMAL) system. ${ }^{18}$ The idea was to design a nuclear powered aircraft that would patrol just outside the enemy's radar range, remaining aloft for weeks or months, carrying ballistic missiles. It was also envisioned that this aircraft would drop down and fly at high speeds below the enemy's radar for a conventional bombing mission. The same idea could be applied to a long endurance aircraft positioned over an enemy or just outside of their radar range. This aircraft could carry missiles, sensors, and/or UAS. The aircraft would patrol on station and launch weapons or sensors to prevent enemy access to the airspace or geographic areas.

\section{E. High Speed Missions}

Many high speed missions exist especially for the military. Civil supersonic flight has been limited to over ocean flight because of the sonic boom noise. It is conceivable that LENR could provide a high speed propulsion system. If the LENR reactor is designed to provide excess energy beyond what is required for the propulsions system, that energy could be used to decrease the aircraft noise and boom levels. Boeing studied future supersonic transports under a NASA contract in 2012. ${ }^{19}$ Table 5 shows the supersonic transport engineering design guidance based on a marketing study they did as part of a NASA contract. To reach supersonic speeds with the desired number of passengers, the aircraft require large engines and large amounts of fuel. LENR could provide the power required with negligible fuel. That means the aircraft could be significantly lighter for the same mission. Figure 8 shows a minimum range of 4,000 nautical miles. LENR could enable longer range supersonic missions, possibly reaching any point on the globe.
Table 5. Boeing's supersonic transport engineering design guidance based on their marketing study ${ }^{19}$

\begin{tabular}{|c|c|}
\hline Marketing Conclusions & Engineering Guideline \\
\hline $\begin{array}{l}100 \text {-150 passengers (in 2-class } \\
\text { arrangement) baseline interior, target } \sim 130 \\
\text { seats }\end{array}$ & $\begin{array}{l}100 \text { pass., } 130+\text { with optional } \\
\text { seating }\end{array}$ \\
\hline $\begin{array}{l}\text { 1.6-1.8 Mach cruise speed \& need } \\
\text { alternative operation plan to increase } \\
\text { utilization (sub-sonic, hybrid } \\
\text { ownership...) }\end{array}$ & 1.8 design limit \\
\hline $\begin{array}{l}\text { Cruise altitude limited to } 55,000 \mathrm{ft} \\
\text { (emissions) }\end{array}$ & $<=55,000 \mathrm{ft}$. \\
\hline $\begin{array}{l}\text { 4,000n.mi. min. supersonic range (trans- } \\
\text { Atlantic +) 6,000n.mi. objective to open } \\
\text { up Asian routes }\end{array}$ & 4,000 n.mi. minimum range \\
\hline $\begin{array}{l}\text { Cruise } \mathrm{M}<=0.95 \text { below } 39 \mathrm{Kft} \text { for ATC } \\
\text { margins. No supersonic speeds below } \\
41 \mathrm{Kft} \text { for ATC margins }\end{array}$ & $\begin{array}{l}\text { Compatible with ATC and traffic } \\
\text { All SS mission }\end{array}$ \\
\hline $\begin{array}{l}\text { Supersonic fuel burn less than } 0.26 \\
\mathrm{lb} / \mathrm{seat} / \mathrm{nmi} \text { ( } 3.8 \text { seat-nmi/lb) set as a } \\
\text { plausible economic and environmental } \\
\text { target }(1 \% \text { / year beyond } \mathrm{N}+2)\end{array}$ & $\begin{array}{l}\text { Study Goal for min fuel aircraft } \\
\text { and point of reference for single } \\
\text { metric designs }\end{array}$ \\
\hline $\begin{array}{l}\text { Sonic boom as low as practical (< } \\
\text { Concorde over-water), consider "threshold } \\
\text { Mach" over-land, and "boom softening" } \\
\text { for operations in coastal regions and } \\
\text { selected over-land corridors }\end{array}$ & $\begin{array}{l}\text { Balanced } 100 \text { Seat config in the } \\
80 \text { PLdB class, "Low Boom" } \\
\text { metric aircraft in the } 70 \text { PLdB } \\
\text { class (eventual goal is } 65-70 \\
\text { PLdB) }\end{array}$ \\
\hline $\begin{array}{l}\text { Over-land and low-yield operational } \\
\text { solution needed }\end{array}$ & $\begin{array}{l}\text { Technology Goals; low boom \& } \\
\text { good fuel efficiency vs. Mach, } \\
\text { possibly "Threshold Mach" cruise }\end{array}$ \\
\hline
\end{tabular}




\section{F. International Cargo Mission}

Currently, long range international cargo transport is dominated by container ships. Two advantages that aircraft provide for this mission are higher speeds and throughput. Boeing designed an aircraft for this mission called the Pelican. ${ }^{20}$ It can carry up to 1,400 tons of cargo. It is designed to fly long range over the ocean about 20 feet above the water. By flying so close to the water it will take advantage of the ground effect. Ground effect is an increase in lift and a decrease in drag resulting from the aircraft flying close to a fixed surface. The ocean can serve as a fixed surface for the Pelican's mission. The Pelican is designed to carry similar cargo to container ships at ten times the speed.

\section{Conclusions}

Rising fuel prices and demand create a societal need for a new source of energy. LENR aircraft propulsion systems enable new mission capabilities, which can create a revolutionary change in the aviation industry. Many alternative sources of energy exist that can be used in aircraft. They all have benefits and add constraints to the aircraft design. The additional systems and storage tanks required for some of the alternative energy sources increase the total aircraft weight. Some energy sources produce energy by fuel consumption which requires replenishment. Harmful emissions are created by some sources that combust fuel. LENR promises few additional systems, negligible fuel consumption, and no harmful emissions.

A high level design space exploration showed that LENR powered aircraft would have extremely long range and endurance. The high power density also allows for high cruise speeds. This technology could enable the use of an abundance of inexpensive energy to remove active design constraints like range and speed, leading to new aircraft designs and missions with negligible fuel consumption, low noise, and no emissions.

LENR aircraft would be well suited for HALE missions. A communications relay mission would have benefits to civilians and the military. Scientific missions for hurricane tracking and other weather phenomena would provide low cost alternatives to satellites. The military's ISR and airspace denial capabilities could be greatly expanded. LENR could provide an affordable design for supersonic passenger transport aircraft and faster international cargo transport.

Future research should explore how LENR will integrate into an aircraft propulsion system. Nuclear propulsions systems may be a good place to start. New technologies like electric propulsion may lead to some unique propulsion system architectures and energy transfer systems. This research is critical to efficiently integrate LENR into aircraft.

If LENR matures to a system suitable for aircraft and fulfills all of the preliminary performance estimates, it would revolutionize the aviation industry and the world. The mission capabilities it may provide are extremely valuable and would give any military a tactical advantage. This exploratory research only gave an idea of LENR applications to synergistic mission capabilities.

\section{Acknowledgments}

First and foremost I would like to thank God for blessing me with talent and a passion for aircraft design. Thank you to everyone that supported and contributed to this paper: Charles Domercant ${ }^{\sharp}$, Prof. Dimitri Mavris $\$$, Michael Miller ${ }^{\ddagger}$, Burak, Bağdatl1 ${ }^{\ddagger}$, Dr. Taewoo Nam, Craig Nickol ${ }^{\S}$, Roger Lepsch ${ }^{\S}$, John Martin ${ }^{\S}$, Joe Zawodny ${ }^{\S}$, Mark Moore ${ }^{\S}$, Mark Guynn ${ }^{\S}$, Bill Fredericks ${ }^{\S}$, Andy Hahn ${ }^{\S}$, James Felder ${ }^{* *}$, Christopher Snyder ${ }^{* *}$, and Dr. Rob McDonald ${ }^{\dagger \dagger}$.

\section{References}

${ }^{1}$ Zawodny, J. M., "Low Energy Nuclear Reactions: Is there a better way to do nuclear power?," NASA Glenn Research Center LENR Workshop, Sep. 2011.

${ }^{2}$ Harris, W., Freudenrich, C. and Fuller, J., "How Nuclear Bombs Work," Oct. 2000, HowStuffWorks.com [online database], URL: http://science.howstuffworks.com/nuclear-bomb.htm [cited Apr. 2014].

${ }^{3}$ Levi, G., et al., "Indication of Anomalous Heat Energy Production in a Reactor Device Containing Hydrogen Loaded Nickel Powder", May 2013, (unpublished).

${ }^{4}$ Fleischmann, M. and Pons, S., "Electrochemically Induced Nuclear Fusion of Deuterium," Journal of Electroanalytical Chemistry, Vol. 261, Issue 2, Part 1, pp. 301-308, Apr. 1989 and errata with Marvin Hawkins in Vol. 263, pp. 187-188, 1989.

\footnotetext{
* Georgia Institute of Technology

$\S$ NASA Langley Research Center

${ }^{* *}$ NASA Glenn Research Center

${ }^{\dagger}$ California Polytechnic State University
} 
${ }^{5}$ Widom, A. and Larsen, L., "Ultra low momentum neutron catalyzed nuclear reactions on metallic hydride surfaces," European Physical Journal C - Particles and Fields, Vol. 46 No. 1, Apr. 2006, pp. 107-111.

6“Annual Energy Outlook 2013 Early Release Overview”, U.S. Energy Information Administration, May 2013.

7"More Fight-Less Fuel," Report of the Defense Science Board Task Force on DoD Energy Strategy, Feb. 2008.

${ }^{8}$ Hendricks, E. S., Berton, J. J., Haller, W. J., Tong, M. T., Guynn, M. D., “Updated Assessments of an Open Rotor Airplane using Advanced Blade Designs", AIAA 2013-3628, 2013.

${ }^{9}$ Bradley, M. K., Droney, C. K., "Subsonic Ultra Green Aircraft Research Phase II: N+4 Advanced Concept Development", NASA CR-2012-217556, May 2012.

${ }^{10}$ Brewer, G. D., "The Case for Hydrogen Fueled Transport Aircraft", AIAA 73-1323, 1973.

${ }^{11}$ Muehlbauer, J. C., "Very Large Aircraft with Alternative Fuels - LH2 Most Promising”, AIAA 82-0813, 1982.

${ }^{12}$ Sloop, J. L., "Liquid Hydrogen as a Propulsion Fuel, 1945-1959”, NASA SP-4404, 1978.

13“Alternative Jet Fuels: A supplement to Chevron's Aviation Fuels Technical Review", Addendum 1 to Aviation Fuels Technical Review (FTR-3/A1), Chevron Corporation, 2006.

${ }^{14}$ Nam, T., “A Generalized Sizing Method for Revolutionary Concepts Under Probabilistic Design Constraints”, Ph.D. dissertation, Georgia Institute of Technology, Atlanta, GA, May 2007.

${ }^{15}$ Nickol, C. L., Guynn, M. D., Kohout, L. L., and Ozoroski, T. A., "High Altitude Long Endurance UAV Analysis of Alternatives and Technology Requirements Development”, NASA TP-2007-214861, Mar. 2007.

${ }^{16}$ Muehlbauer, J. C., et al., "Innovative Aircraft Design Study, Task II: Nuclear Aircraft Concepts”, ADB017795, LockheedGeorgia Company, Marietta, GA, Apr. 1977.

17"RQ-4 Global Hawk", Northrop Grumman Corporation Factsheet, May 2008.

${ }^{18}$ Cortright, V., "Dream of Atomic Powered Flight", Aviation History Magazine, Mar. 1995.

${ }^{19}$ Welge, H. R., et al., "N+3 Advanced Concept Studies for Supersonic Commercial Transport Aircraft Entering Service in the 2030-2035 Period", NASA CR-2011-217084, Apr. 2011.

${ }^{20}$ Cole, W., "The Pelican: A big bird for the long haul," Boeing Frontiers online, Vol. 1, No. 5, Sep. 2002. 